\title{
EL TRIBUNAL CONSTITUCIONAL ANTE LA RECIENTE REFORMA DE LOS ARTÍCULOS 16 DE SU LEY ORGÁNICA Y 184 DEL REGLAMENTO DEL SENADO
}

PATRICIA RODRÍGUEZ-PATRÓN 


\section{SUMARIO}

I. INTRODUCCIÓN. II. LA PARTICIPACIÓN DE LAS ASAMBLEAS LEGISLATIVAS DE LAS CCAA EN LA ELECCIÓN DE LOS MAGISTRADOS DESIGNADOS POR EL SENADO. III. LA STC 49/2008 ANTE EL NUEVO APARTADO TERCERO DEL ARTÍCULO 16 LOTC: PRÓRROGA DEL CARGO DE PRESIDENTE 


\title{
EL TRIBUNAL CONSTITUCIONAL ANTE LA RECIENTE REFORMA DE LOS ARTÍCULOS 16 DE SU LEY ORGÁNICA Y 184 DEL REGLAMENTO DEL SENADO
}

\author{
POR \\ PATRICIA RODRÍGUEZ-PATRÓN \\ Profesora Titular de Derecho Constitucional \\ Universidad Autónoma de Madrid
}

\section{INTRODUCCIÓN}

Dos recientes reformas normativas han afectado de forma polémica a la composición y al funcionamiento del Tribunal Constitucional. Por un lado, la Ley Orgánica 6/2007, de 24 de mayo, que aborda de forma conjunta algunas dificultades de éste en su modo de funcionar ${ }^{1}$. Por otro lado, la reforma del Re-

\footnotetext{
${ }^{1}$ Un completo estudio sobre esta reforma, que incluye un comentario a la STC 49/2008 (pp. 261 y ss.), puede encontrarse en M. CARRILLO (coord.), Hacia una nueva jurisdicción constitucional. Estudios sobre la Ley 6/2007, de 24 de mayo de Reforma de la LOTC, Tirant lo Blanch Alternativa, 2008.

Analiza también los aspectos más destacables de la nueva Ley M. ARAGÓN REYES en «La reforma de la Ley Orgánica del Tribunal Constitucional», REDC núm. 85, 2009, pp. 11-43.

En sentido muy crítico con la nueva regulación (tanto respecto al fondo, como a la forma) se manifiesta J. L. REQUEJO PAGÉS en «Doctrina del Tribunal Constitucional durante el segundo cuatrimestre de 2007», REDC núm. 81, 2007, pp. 221-242.
} 
glamento del Senado en lo que se refiere al modo de elección de los candidatos que han de ser propuestos por esa Cámara para ocupar el cargo de Magistrado del TC.

La LO 6/2007 introduce en un segundo párrafo del apartado 1 del artículo 16 LOTC la siguiente previsión: «Los Magistrados propuestos por el Senado serán elegidos entre los candidatos presentados por las Asambleas Legislativas de las Comunidades Autónomas en los términos que determine el Reglamento de la Cámara». El Reglamento del Senado, por su parte, ha establecido, como veremos, "en qué términos» se producirá esa elección dentro de la Cámara Alta.

La citada reforma de la LOTC incorpora, de manera igualmente polémica, la prórroga del mandato del Presidente y el Vicepresidente una vez expirado éste en caso de no haberse producido la renovación del Tribunal (art. 16.3).

En relación con estas dos novedades normativas, se han presentado dos recursos de inconstitucionalidad que han sido resueltos, respectivamente, por las Sentencias 49/2008 y 101/2008. Aquí realizaremos nuestro comentario a las mismas de acuerdo con el objeto de impugnación. Analizaremos, en primer lugar, el problema que se refiere a la participación de las Asambleas Legislativas de las CCAA en la propuesta de los candidatos a Magistrados del TC. A él se refieren tanto la STC 49/2008 como la STC 101/2008. La primera de ellas, al resolver el recurso de inconstitucionalidad contra el párrafo segundo del apartado primero del reformado artículo 16 LOTC. La segunda, en respuesta al recurso de inconstitucionalidad contra el nuevo apartado séptimo del artículo 184 RS. Posteriormente, analizaremos el asunto de la prórroga del mandato del Presidente y del Vicepresidente, resuelto por la primera de las Sentencias antes aludidas.

\section{LA PARTICIPACIÓN DE LAS ASAMBLEAS LEGISLATIVAS DE LAS CCAA EN LA ELECCIÓN DE LOS MAGISTRADOS DESIGNADOS POR EL SENADO}

Uno de los rasgos por los que se reconoce la especial posición del Tribunal Constitucional es el hecho de que los demás órganos constitucionales participan en la elección de sus miembros (art. 159.1 CE). En relación con este modo de elección, la reforma operada en el artículo 16.1, segundo párrafo LOTC fue

Más benévolo se muestra con esta reforma, así como con las Sentencias comentadas, I. TORRES MURO, «La reforma de la Ley Orgánica del Tribunal Constitucional y del Reglamento del Senado, puesta a prueba (SSTC 49/2008, de 9 de abril y 101/2008, de 24 de julio", en Revista General de Derecho Constitucional núm. 6, www.iustel.com. 
muy controvertida desde su inicio, contando ya en el Congreso con el voto en contra de varios grupos parlamentarios ${ }^{2}$.

\subsection{El recurso de inconstitucionalidad contra los apartados primero (párrafo segundo) y tercero del artículo 16 LOTC $^{3}$ resuelto por la STC 49/2008, de 9 de abril}

El primero de los preceptos impugnados en el recurso de inconstitucionalidad presentado por 50 diputados pertenecientes al Grupo Popular se introduce en un segundo párrafo del apartado 1 del artículo 16 LOTC, cuyo contenido se refiere a la presentación por parte de las Asambleas Legislativas de las CCAA de candidaturas para Magistrados del TC, en los términos que hemos señalado más arriba.

Junto con la previsión de la prórroga del mandato del Presidente y el Vicepresidente, consideran los recurrentes que este precepto altera sustancialmente el modelo organizativo del Tribunal Constitucional derivado del Título IX CE, sin que el legislador haya justificado lo más mínimo dichos cambios en la Exposición de Motivos de la Ley Orgánica 6/2007, de donde deducen que su actuación ha sido puramente arbitraria ${ }^{4}$.

En concreto, los recurrentes hacen girar sus argumentos contra lo dispuesto en este nuevo apartado, principalmente, en torno a dos tipos de objeciones ${ }^{5}$. Las

${ }^{2}$ Esta participación es analizada de forma pormenorizada por J. F. SÁNCHEZ BARRILAO en el sugerente estudio «La participación de las Comunidades Autónomas en la elección por el Senado de los Magistrados Constitucionales», Teoría y Realidad Constitucional, núm. 23, 2009, pp. 387 y ss. En dicho trabajo se incluye un comentario de las Sentencias aquí analizadas en relación con este asunto desde una perspectiva distinta a la que aquí ofreceremos.

3 Ambos apartados son introducidos por el artículo único, apartados 6 y 7 , respectivamente, de la Ley Orgánica 6/2007, de 24 de mayo.

${ }^{4}$ V. el Antecedente primero, apartado d). El TC dedica el F. J. $5^{\circ}$ a negar que se produzca tal arbitrariedad y posteriormente se reafirma en tal apreciación, al hilo de la resolución de las concretas objeciones planteadas por los recurrentes.

No obstante, el TC ya ha mostrado su criterio al respecto en otras ocasiones, en cuanto a que «la calificación de «arbitraria» dada a una Ley a los efectos del art. 9.3 de la Constitución exige una cierta prudencia» (STC 104/2000, de 13 de abril, F. J. $8^{\circ}$ ). Pues, la amplia libertad de configuración del legislador, derivada de su posición constitucional, obliga al Tribunal Constitucional a la hora de realizar el control de constitucionalidad a respetar sus opciones políticas siempre y cuando, naturalmente, no vulneren ningún precepto constitucional.

Sobre este asunto, v. I. TORRES MURO, op. cit., pp. 6 y ss.

5 Junto a ellas, se plantean otras objeciones accesorias, sobre las que no nos pronunciaremos aquí. V. F. J. 1.

(C) UNED. Revista de Derecho Político

N. ${ }^{\circ} 77$, enero-abril 2010, págs. 107-140 
primeras, que podríamos denominar formales, se refieren al ámbito de las fuentes del Derecho. Las segundas defienden la inconstitucionalidad material o de fondo del precepto impugnado. Para una mejor exposición de mi visión de este asunto, me referiré en primer lugar, a estas últimas.

\subsubsection{Las objeciones de carácter material}

Los recurrentes consideran que la reforma del artículo 16.1 LOTC vulnera frontalmente lo dispuesto en el art. 159.1 y en todo el Título III CE6 . Con ella — entienden - se sustituye en el fondo una elección de primer orden por una de segundo orden, que opera a partir de las propuestas de las Asambleas autonómicas. La declaración de constitucionalidad de la reforma — añaden — sería peligrosa, pues el modelo podría extenderse a la designación de otros Magistrados del TC, de los vocales del Consejo General del Poder Judicial o a la designación de Ministros o de los propios miembros de las Cámaras. En definitiva, consideran que una regulación así reconduce la actuación del Senado a poco más que una formalidad.

El hecho de que el Senado sea la cámara de representación territorial tampoco les resulta suficiente para justificar la reforma en este punto. Es más, considera la demanda que, en realidad, se trata de una sustitución inadmisible de los poderes del Estado por las instituciones autonómicas y una autodisolución de los órganos de representación nacional, que coloca a la Cámara Alta en una situación de discriminación respecto al Congreso de los Diputados?

Con carácter previo a la resolución de esta cuestión el TC se plantea si es posible y, en caso afirmativo, cómo ha de llevarse a cabo el control de constitucionalidad de su propia Ley Orgánica. Porque, como señala al inicio del Fundamento Jurídico segundo, este recurso les ha puesto en la tesitura de controlar la única ley a la que están íntegramente sometidos.

No habiendo antecedentes que resulten enteramente aplicables, el TC analiza la cuestión desde puntos de vista formales y materiales. Así, formalmente, no hay motivos procesales para rechazar la posibilidad de tal control: «No hay duda que los preceptos impugnados constituyen disposiciones normativas con

${ }^{6}$ En especial, los arts. 66, 67, 69, 70, 71,72, 73, 74, 75, 76, 77, 78, 79, 80, 82.

7 De ahí se derivaría, asimismo, una infracción de la prohibición del mandato imperativo (art. 67.2 CE), del artículo 23.2 CE y, por extensión, del derecho de participación política de los ciudadanos representados (art. 23.1 CE), que el TC rechaza de plano como consecuencia de la negación de las objeciones principales y en la que aquí no nos vamos a detener. 
fuerza de ley [arts. 161.1 a) CE y 33.1 LOTC] y, más concretamente, normas con rango de ley orgánica, y que, como prevé expresamente el art. 27.2 a) LOTC, son susceptibles de ser declaradas inconstitucionales por este Tribunal» ${ }^{8}$. Tampoco habría obstáculos desde el punto de vista material. Lo contrario — se señala— «supondría no sólo admitir una zona inmune al control de constitucionalidad, sino también hacer dejación de nuestra función en un ámbito tan decisivo para la propia supremacía de la Constitución como la jurisdicción de este Tribunal»".

Sin embargo, en lo que se refiere al alcance del control, el Tribunal entiende que, dada la vinculación del órgano a la LOTC, la fiscalización «debe limitarse a los supuestos en que existe un conflicto evidente e insalvable entre la misma y el texto constitucional $»^{10}$. No entendemos el por qué de esta diferenciación respecto a la fiscalización del resto de las leyes. Al legislador lo que es del legislador y al TC lo que es del TC. Al primero le corresponde la competencia para efectuar la regulación reservada en el art. $165 \mathrm{CE}$, y al segundo controlar que esa regulación — exactamente igual que cualquier otra - se realiza conforme a la Constitución. Porque la vinculación del órgano a la ley dejará de ser tal si ésta se declara inconstitucional. Coincidimos, pues, con lo señalado por el Magistrado Don Javier Delgado Barrio en su voto particular: «Ciertamente y con carácter general este Tribunal está vinculado por su Ley Orgánica, pero cuando ésta es objeto de un recurso de inconstitucionalidad, la sujeción del Tribunal a su Ley Orgánica queda sustituida por la posición de órgano de control de la constitucionalidad de la ley [...], habilitado, en su caso, para expulsar el precepto impugnado del ordenamiento jurídico» ${ }^{11}$.

Una vez aclarado este punto, inicia el TC su análisis de la constitucionalidad del precepto enjuiciado, desde esta perspectiva material. Para ello, propone no interpretarlo aisladamente, sino en el contexto de las normas que integran todo el Título IX CE y, en general, del modelo de Tribunal Constitucional que se deriva de nuestra Norma Suprema.

El Alto Tribunal comienza realizando unas consideraciones en torno al parámetro de control. Así, señala que el artículo 159.1 CE, que pretende la parti-

${ }^{8}$ F. J. 3, primer párrafo.

${ }^{9}$ F. J. 3, párrafo cuarto.

10 F. J. 4, segundo párrafo.

${ }^{11}$ En este sentido se manifiesta también J. L. REQUEJO PAGÉS («Doctrina del Tribunal Constitucional durante el primer cuatrimestre de 2008», en REDC, núm. 83, 2008, pp. 209-242), pg. 212, quien coincide con Delgado Barrio en que, en todo caso, el control de constitucionalidad de la LOTC debería ser "particularmente incisivo y profundo».

V., asimismo, I. TORRES MURO, op. cit., pp. 4 y ss. 
cipación de diversos órganos constitucionales en la elección de los Magistrados, no cierra las puertas en modo alguno a que otras normas puedan desarrollar una regulación constitucional «que, entre otras cosas, guarda silencio sobre el procedimiento a seguir en dicha elección». A ello hay que añadir que la elección de los miembros del Tribunal no puede desvincularse de los requisitos de elegibilidad, capacidad e independencia establecidos por los apartados segundo, cuarto y quinto de ese mismo artículo. También habrá de respetar el sistema de renovación por bloques de la renovación periódica del órgano (art. 159.3) ${ }^{12}$.

En cuanto al problema de si la norma impugnada vacía de contenido la atribución constitucional al Senado, la respuesta del TC es negativa según un doble orden de consideraciones. En primer lugar, respecto a la fase que tiene lugar en los Parlamentos autonómicos, la presentación de candidaturas a Magistrado. Nada se dice sobre el procedimiento a seguir, ni del número ni de las condiciones que han de cumplir los candidatos que cabe presentar, ni de si es posible la presentación de candidaturas sucesivas por el Senado o las Asambleas autonómicas. Por ello, los Reglamentos del Senado y de las Asambleas de las CCAA, dentro de su respectivo ámbito de actuación, deben concretar el régimen jurídico de dicho deber. En la segunda fase, de elección de los Magistrados por parte del Senado, lo único que exige el nuevo precepto de la LOTC es que se produzca «entre» los candidatos presentados por las Asambleas Legislativas autonómicas. Y, de nuevo, el precepto se remite expresamente «a los términos que determine el Reglamento de la Cámara». Ello supone que al Senado se le permite velar por el ejercicio constitucionalmente correcto de su función «si, por ejemplo, el número de candidatos presentados es insuficiente, si considera que los candidatos propuestos no cumplen los requisitos exigidos constitucionalmente, o si la elección de algunos de los Magistrados se frustra por no alcanzarse la mayoría requerida». De ahí deduce el TC que la «efectiva renuncia, traslado o sustitución del Senado por parte de los Parlamentos autonómicos» dependerá de la regulación que realice la Cámara Alta en su Reglamento ${ }^{13}$. Es decir, que de haber alguna norma inconstitucional, ésta podría encontrarse en el Reglamento, si con sus disposiciones provoca, de hecho, una renuncia de la función de la Cámara.

El TC rechaza a continuación el planteamiento de los recurrentes que presenta la facultad del Senado como absoluta e ilimitada. La elección de sus Magistrados por parte del Senado «es un aspecto que requiere necesariamente des-

${ }^{12}$ V. F. J. 7.

${ }^{13}$ El TC entiende que no cabe un pronunciamiento preventivo sobre el contenido del Reglamento del Senado, de acuerdo con lo que ha establecido en su jurisprudencia reiteradamente (F. J. 9, último párrafo). 
arrollo normativo y que, por tanto, puede verse limitada tanto material como procedimentalmente». Pero — reconoce— «la norma recurrida presenta un elemento cualitativo diferente, cual es el de introducir por vez primera la participación de órganos ajenos al Senado» en dicha elección. Este hecho le obliga a analizar tres cuestiones.

La primera de ellas, si la participación de los parlamentos autonómicos prevista en la reforma está constitucionalmente prohibida. A ella —entiende el Tribunal — ha de contestarse necesariamente de forma negativa. Porque «la Constitución no se limita a ser un conjunto de normas que deben ser ejecutadas o un programa que debe ser desarrollado, sino un marco de coincidencias lo suficientemente amplio como para que dentro del mismo quepan opciones políticas de diverso signo»" ${ }^{14}$.

Pero el TC se pregunta también si la finalidad perseguida por la reforma es legítima en este punto desde una perspectiva constitucional. Y, en su opinión, lo es, dada la definición del Senado como Cámara de representación territorial en el art. 69 CE. En este sentido, la decisión de atribuir la elección de cuatro Magistrados a esta Cámara en los mismos términos que el Congreso de los Diputados «ya denota una voluntad constitucional inequívoca de integrar la estructura territorial del Estado en la composición del Tribunal Constitucional» ${ }^{15}$.

En tercer lugar, se plantea el Alto Tribunal si la norma puede ser tachada de inconstitucional por su intensidad y resultado. La respuesta vuelve a ser aquí negativa, pues entiende que, tal y como está redactado el precepto, no se impide "que el Senado pueda hacer frente a los problemas que pueden derivarse de la inactividad de los Parlamentos autonómicos o de la frustración de sus propuestas». Por todo ello — continúa el TC— «no puede considerarse, como aducen los recurrentes en algún momento, que la norma impugnada sustrae una atribución constitucional que se califica de mínima y se vincula con la garantía institucional de esta Cámara». Incluso - llega a afirmar nuestro Alto Tribunal—, «el tenor literal del art. 16.1 de la LOTC permite que el Reglamento del Senado pueda, entre otras fórmulas, prever, incluso, mecanismos que hagan posible que sea la propia Cámara la que proponga candidatos a Magistrados del Tribunal Constitucional en el supuesto excepcional de que el sistema de elección de dichos Magistrados previsto con carácter general no culmine con esta elección, garantizando así que la Cámara Alta cumpla con la obligación constitucional» ${ }^{16}$.

${ }^{14}$ F. J. 12.

15 F. J. 13. El TC hace alusión también a que esta idea estuvo muy presente en el proceso constituyente y, sobre todo, en la elaboración del art. 159 CE.

${ }^{16}$ F. J. 14. 
Nos parece claro que el controvertido precepto plantea dudas más que razonables en cuanto a su constitucionalidad. Pero, a nuestro modo de entender, estas dudas no se ven despejadas con los argumentos ofrecidos por el Tribunal en el párrafo precedente. Nos parece - y en ello coincidimos con el voto particular del Magistrado Vicente Conde- que «el tenor literal» del nuevo art. 16.1 LOTC no permite una interpretación semejante. Todo lo contrario, consideramos que desvirtúa completamente el sentido del mismo.

Descartada esta última argumentación, nos detendremos ahora en los otros dos pilares del razonamiento jurisprudencial del TC. En primer lugar, en la cuestión de si la regulación del art. 159 CE puede considerarse o no cerrada en lo que se refiere a la elección de los Magistrados del TC (apartados 1 y 2).

Parece evidente que, desde el punto de vista procedimental no lo es, pues nada dice su apartado primero respecto a cómo han de proceder los órganos constitucionales citados a la hora de proponer los candidatos por ellos elegidos. Atribuida la elección a los distintos órganos constitucionales, se estaría dejando a su autonomía la regulación del procedimiento para llevarla a cabo.

Ahora bien, en lo que se refiere a los órganos que han de elegirlos y las condiciones que han de cumplir los candidatos para poder ser seleccionados la regulación contenida en estos artículos sí parece ser una regulación cerrada. El apartado primero determina quién elige a los Magistrados y el apartado segundo «entre» quiénes pueden elegirlos. De haber querido el constituyente abrir las puertas a nuevas especificaciones no procedimentales lo habría tenido muy fácil. Podría haber repetido el modelo del art. 122.3 CE en el que se prevé que la propuesta de los 12 vocales del Consejo General del Poder Judicial que deben ser elegidos entre Jueces y Magistrados de todas las categorías judiciales se verificará «en los términos que establezca la ley orgánica».

Que la Constitución haya querido que la Cámara de representación territorial (órgano estatal) tuviera una participación importante en la formación del TC no quiere decir, ni mucho menos, que se estuviera pensando en la participación de las CCAA en la elaboración de la lista de los elegibles por el Senado. Entre otras cosas, porque en el momento constituyente ni siquiera se sabía si España cuajaría como el Estado autonómico que es hoy ${ }^{17}$.

Si analizáramos la cuestión desde el punto de vista expuesto, no cabría otra alternativa que considerar inconstitucional tal participación. Sin embargo, son otras - nos parece — las consideraciones que están detrás de la decisión del Tri-

17 A ello hace referencia el TC en el F. J. 12, segundo párrafo, como sustento de su interpretación abierta del artículo 159. 
bunal. Como es de sobra conocido, el Senado no cumple de forma satisfactoria con su papel de Cámara de representación territorial que el artículo 69.1 CE proclama. La solución que el legislador aporta ahora se enmarca dentro de una corriente (política, pero también jurídica) que, desde hace ya algunos años, trata de «moldear» el papel del Senado dentro del Estado (a través de reformas reglamentarias y legales) para fortalecer su dimensión territorial, en tanto no se produzca una reforma constitucional. Así se pone de manifiesto en el Fundamento Jurídico 9 de la Sentencia, donde se hace referencia al proceso de elaboración del precepto impugnado y a las enmiendas presentadas con la finalidad de introducir algún mecanismo de participación de las Comunidades Autónomas en la designación de Magistrados por parte del Senado.

A nuestro modo de ver, el TC realiza un análisis del artículo 159 CE que atiende sobre todo, no a las circunstancias que rodearon su redacción en el momento constituyente, sino a estas nuevas exigencias sociales, políticas y jurídicas respecto a la Cámara Alta ${ }^{18}$. Conforme a ellas, lleva a cabo una interpretación del precepto asumible e -incluso- deseable, en tanto contribuye a evitar el malestar que puede provocar la discordancia entre lo político y lo jurídico y, con ello, a asegurar la estabilidad de la Constitución ${ }^{19}$.

Por eso no nos convencen —entre otras $\operatorname{cosas}^{20}$ — las objeciones planteadas por los recurrentes en cuanto a que una reforma así puede abrir las puertas a otras que impongan legalmente condiciones a la elección de los demás Magistrados del TC o de los miembros de otros órganos constitucionales. En estos casos (elección de los Vocales del CGPJ que derivan de la Constitución por el Congreso, elección de los Magistrados del TC por el Gobierno, designación de los Ministros o de los miembros de las Cámaras) faltaría una justificación compatible actualmente con la Constitución.

Una vez admitida la compatibilidad con la Norma Fundamental de la participación de las CCAA en la elección de los Magistrados, queda preguntarse to-

18 A esta visión del Senado y del papel que deben cumplir dentro del Estado las Comunidades Autónomas se refiera M. CARRILLO en «El Senado de las Autonomías», publicado en el diario «El País», en su edición del día 17 de julio de 2008 [recogido también en la revista de prensa del Diario del Derecho de IUSTEL, en su edición del día 18 de julio de 2008 (www.iustel.com)]. V., también, Ángel L. Sanz Pérez, "Comentario a la STC 49/2008. las fuentes del Derecho Parlamentario y el Senado", Repertorio Aranzadi del Tribunal Constitucional núm. 9/2008, BIB $\underline{2008 \backslash 1457 .}$

19 Ello, por supuesto, no resta un ápice de importancia a la necesidad de una reforma constitucional del Senado y de los mecanismos de participación de los entes territoriales en la toma de decisiones del Estado.

${ }^{20}$ Otros argumentos ofrece el TC en el penúltimo párrafo del F. J. 14. 
davía si el medio utilizado para prever dicha participación — la reforma de la LOTC - es el adecuado desde el punto de vista constitucional.

\subsubsection{Las objeciones de carácter formal: idoneidad de la LOTC para regular} esta materia

Las objeciones de índole formal se sitúan en el ámbito de las fuentes del Derecho. En resumidas cuentas, plantean los recurrentes que la LOTC no es norma idónea para regular esta materia. En su caso — mantienen-, dicha reforma debería haberse introducido a través del Reglamento del Senado. El método empleado es, en consecuencia, invasivo de la reserva establecida respecto a dicho reglamento en el art. $72 \mathrm{CE}$.

La reforma excedería, además, de la reserva de ley orgánica contenida en el art. $165 \mathrm{CE}$. Porque se refiere al funcionamiento de otro órgano (el Senado) y a la elección previa de los Magistrados, por lo que no puede incluirse ni en la regulación del funcionamiento del Tribunal, ni del estatuto de sus miembros, ni del Derecho procesal constitucional.

Por último, se denuncia la utilización de esta Ley Orgánica para otorgar a las Asambleas autonómicas competencias no previstas constitucionalmente. A su modo de ver, una ley orgánica del art. $81 \mathrm{CE}$ no puede alterar la distribución de competencias para —además - desapoderar a un órgano constitucional del Estado y sustituirlo por ámbitos parciales de representación de cada Asamblea.

Los argumentos del TC, en contra del planteamiento de los recurrentes, se centran, primeramente, en la negación de la existencia de una vulneración del art. 72.1 CE. Por un lado, porque la regulación controvertida excede claramente de la vida interna del Senado, al prever la participación de los Parlamentos autonómicos en la elección de los Magistrados del Tribunal. Como dicha participación va más allá de un mero trámite de audiencia o de consulta, el Reglamento del Senado no podría realizar unilateralmente tal previsión. Pero es que, por otro lado, la regulación legal contiene una amplia remisión al Reglamento de la Cámara, lo que garantiza que sea ésta la que concrete libremente el régimen jurídico de la participación autonómica y del procedimiento de elección definitiva de los Magistrados.

Por lo que respecta a lo establecido en el artículo $165 \mathrm{CE}$, el TC no encuentra tacha alguna de inconstitucionalidad. Y ello por los términos en que se formula la reserva ("Una ley orgánica»), la amplitud de las materias aludidas («el funcionamiento del Tribunal Constitucional, el estatuto de sus miembros, el procedimiento ante el mismo y las condiciones para el ejercicio de las acciones»), 
su posición de cierre del Título IX, y el hecho de proyectarse sobre un órgano como el Tribunal Constitucional. Todo esto le otorgaría —en opinión del TC - una vocación de complitud que impide una interpretación restrictiva de tales materias. En resumen, «únicamente la LOTC y no cualquier otra ley puede desarrollar la institución del Tribunal Constitucional en todos sus ámbitos en que quepa tal desarrollo, bien por requerirlo la Constitución, bien porque no esté constitucionalmente impedido» ${ }^{21}$.

No podemos coincidir, en esta ocasión, con la argumentación del Tribunal, y no sólo por razones teóricas, sino también por otras de índole práctica que trataremos de exponer a continuación.

Según nuestro criterio, la vía constitucionalmente adecuada para hacer partícipes a las CCAA en la elección de los Magistrados del TC es, simplemente, la reforma del Reglamento del Senado ${ }^{22}$. Es a esta Cámara a la que la Constitución atribuye la función de elegir a cuatro de ellos. Es, por tanto, al Senado al que le corresponde determinar reglamentariamente el procedimiento a seguir en el ejercicio de esa función propia. Y no es obstáculo - me parece- el hecho de que tal regulación vaya más allá de la estricta «vida interna del Senado». De hecho, el TC se apresura inmediatamente (y dedica una parte importante de su argumentación) a aclarar que, pese a no corresponderle la competencia reguladora en esta materia, la autonomía normativa del Senado queda plenamente garantizada, porque la ley deja abierta diversas posibilidades de regulación ${ }^{23}$. Permite, incluso, que en uso de esa autonomía establezca fórmulas de participación de las CCAA que - siempre según nuestro modo de ver - resultan incompatibles con el tenor literal del precepto legal controvertido. También nos parece significativo que el Tribunal, al defender una visión del artículo 159 CE como norma abierta al desarrollo normativo, señala las diversas especialidades del

\footnotetext{
${ }^{21}$ V. F. J. 14.

${ }^{22}$ Coincidimos en este punto con el Magistrado Vicente Conde en su voto particular.

En esta misma línea, J. L. REQUEJO PAGÉS, REDC, núm. 83, op. cit., pg. 213 y C. J. Fernández-Carnicero González, «La STC 49/2008, una sentencia desfalleciente», Repertorio Aranzadi del Tribunal Constitucional núm. 10/2008, BIB 2008\1743.

En contra, I. TORRES MURO, op. cit., pp. 8 y ss.

${ }^{23}$ V. F. F. J. J. 14 y 15.

El Magistrado Vicente Conde, en su voto particular, hace referencia a una cierta contradicción que es posible también apreciar: «Si el carácter de Cámara de representación territorial del Senado, según se sostiene en el texto de la Sentencia, vale para incluir en su función la participación autonómica que nos ocupa, no veo lógica coherencia en la negación de que el Reglamento de esa Cámara pueda regular una función que previamente se ha insertado en el propio carácter de la misma».
} 
procedimiento que se han ido fijando a lo largo del tiempo, pero siempre en el Reglamento de la Cámara Alta ${ }^{24}$.

Según nuestra concepción de la autonomía reglamentaria de los órganos constitucionales, ésta tiene un marcado carácter funcional o instrumental, de forma que el ámbito concreto sobre el que pueden recaer sus productos normativos ha de determinarse, principalmente, no de acuerdo con criterios personales, sino funcionales ${ }^{25}$. Eso supone admitir en muchos casos cierta eficacia ad extra de este tipo de reglamentos, siempre que la regulación contenida en los mismos se refiera al ejercicio de sus funciones.

Respecto al caso que nos ocupa, el Senado puede perfectamente considerar necesaria para llevar a cabo correctamente su función constitucionalmente asignada la colaboración de los Parlamentos autonómicos en la configuración de una lista de elegibles como candidatos al TC y, por tanto, incluirla en su Reglamento. Lo más adecuado y respetuoso con la autonomía de las distintas CCAA es que tal colaboración se establezca (como de hecho se hace en la regulación actual de este Reglamento) en términos de posibilidad.

Nos parece mucho más clara la competencia del Senado para regular este procedimiento que la del legislador para hacerlo a través de la LOTC, pues no hay aquí una remisión similar a la del art. 122.3 CE y no nos resulta tan evidente como al TC que el art. $165 \mathrm{CE}$ le autorice a ello bajo el paraguas del «estatuto de sus miembros ${ }^{26}$. En ello coincidimos con lo expuesto en su voto particular por el Magistrado Vicente Conde, pues nos parece que «la composición del Tribunal es algo anterior y distinto a las materias a que este precepto se refiere».

A las consideraciones realizadas hasta aquí debemos añadir otras que se refieren a la situación normativa creada de facto por la regulación legal impugnada y por la interpretación que de ella ha realizado el TC. Por un lado, nos encon-

24 V. F. J. 10.

25 Esta concepción funcional o instrumental de la autonomía normativa de los órganos constitucionales, que admite una cierta eficacia ad extra de la misma, la hemos defendido anteriormente, en relación con el Tribunal Constitucional, en P. RODRÍGUEZ-PATRÓN: La potestad reglamentaria del Tribunal Constitucional, ed. Iustel, Madrid 2005, especialmente, pp. 61 y ss y 128 y ss.

${ }^{26} \mathrm{Y}$ no es aceptable de ninguna manera la alegación del Abogado del Estado (aunque él mismo reconoce que no es un argumento de constitucionalidad), en el sentido de que el Senado, al contribuir a la aprobación de esta ley "ha consentido lo que los recurrentes consideran un desapoderamiento de sus funciones constitucionales». De acuerdo con ese criterio, podría prescindirse siempre de la potestad reglamentaria de las Cámaras, dado que éstas cuentan con potestad legislativa. 
tramos con el artículo 16.1 LOTC que parece establecer de forma imperativa la participación de los Parlamentos autonómicos en la elección de los cuatro Magistrados designados por el Senado, mediante la presentación de candidatos (lo cual plantearía otra duda - expuesta por los recurrentes y no resuelta frontalmente por el TC - sobre la idoneidad de la LOTC para asignarles esa función). El precepto establece claramente que «Los Magistrados propuestos por el Senado serán elegidos entre los candidatos presentados por las Asambleas Legislativas de las Comunidades Autónomas [...]». No podemos compartir la posición que el Abogado del Estado formula explícitamente - y que el TC parece asumir de forma implícita-, que ve en este artículo simplemente la formulación de un derecho por parte de las Asambleas Legislativas autonómicas para presentar candidaturas a Magistrado ${ }^{27}$.

Por otro lado, el apartado séptimo del art. 184 de Reglamento del Senado (en su redacción dada por la reforma de 21 de noviembre de 2007) prevé esa participación, como señalaremos más adelante, en términos de posibilidad oaquí sí- como derecho de presentación de candidatos [letra a)]. Además, permite que el Senado termine realizando su elección pese a no producirse propuestas autonómicas o si estas son insuficientes [letra b)].

La contradicción, que parece clara, ha sido salvada gracias a la interpretación («abierta», también en este caso) ofrecida por el TC en la Sentencia que comentamos. Como hemos visto, según esa interpretación, el art. 16.1 LOTC permite que el Reglamento del Senado establezca distintas fórmulas de actuación en este procedimiento. Y, especialmente, afirma la constitucionalidad de una fórmula como la empleada por el nuevo apartado 7 del art. 184 del Reglamento del Senado que hace posible «que sea la propia Cámara la que proponga candidatos a Magistrados del Tribunal Constitucional en el supuesto excepcional de que el sistema de elección de dichos Magistrados previsto con carácter general no culmine con esta elección, garantizando así que la Cámara Alta cumpla con su obligación constitucional» ${ }^{28}$.

No le falta razón al Magistrado Vicente Conde cuando afirma en su voto particular que, en realidad, lo que se hace es salvar la constitucionalidad del precepto «a base de difuminar el sentido claro de lo que dice». Como hemos señalado anteriormente, afirmada ya la constitucionalidad de la reforma en este punto (pues se redacta de forma abierta), la inconstitucionalidad sólo cabría en alguna de las concreciones que pudieran contenerse en el Reglamento del Se-

${ }_{27}^{27}$ V. Antecedente $9 \mathrm{c}$ ), párrafo $7^{\circ}$.
${ }_{28}$ F. J. 14, último párrafo. 
nado si — se entiende — no garantiza el «cumplimiento de su obligación constitucional $»^{29}$.

Con todo ello, el TC adelanta el pronunciamiento que tiene lugar posteriormente en la resolución del recurso de inconstitucionalidad frente a la reforma del Reglamento del Senado en este punto, mediante la STC 101/2008, a la que nos referiremos seguidamente, con la que confirma esta interpretación de la norma legal. Pero — nos parece- el panorama normativo diseñado por el TC complica innecesariamente las cosas que, creemos, resultan más sencillas (al menos, desde el punto de vista jurídico) afirmando simplemente la competencia del Senado para fijar reglamentariamente esta materia.

\subsection{El recurso de inconstitucionalidad contra el apartado séptimo del artículo 184 del Reglamento del Senado, resuelto por la STC 101/2008, de 24 de julio}

Con la aprobación de la reforma del Reglamento del Senado, se plantea un nuevo recurso de inconstitucionalidad ante el TC. El recurso se presenta por cincuenta y dos senadores del Grupo Parlamentario Popular. En este caso se dirige contra el nuevo apartado 7 del art. 184 de dicho Reglamento, introducido por el Artículo único de la Reforma, aprobada el 21 de noviembre de 2007, que establece lo siguiente:

«La elección por el Senado de los cuatro Magistrados del Tribunal Constitucional, cuyo nombramiento ha de proponerse al Rey, según lo previsto en el artículo 159 de la Constitución, seguirá el procedimiento previsto en este Capítulo con las siguientes especialidades:

a) El Presidente del Senado comunicará a los Presidentes de las Asambleas Legislativas de las Comunidades Autónomas la apertura del plazo para la presentación de las candidaturas. Cada Asamblea Legislativa podrá, en ese plazo, presentar hasta dos candidatos, resultando aplicable lo dispuesto en los apartados 3 y 4 de este artículo.

b) La Comisión de Nombramientos elevará al Pleno de la Cámara una propuesta con tantos candidatos como puestos a cubrir, que deberán haber comparecido previamente en la Comisión. Si no se hubieran presentado en plazo candidaturas suficientes, la propuesta que se eleve al Pleno podrá incluir otros candidatos».

${ }^{29}$ El TC lo da a entender así, cuando, en el tercer párrafo del F. J. 15, hace alusión a las diversas posibilidades que deja abiertas el texto legal «que no nos corresponde analizar en este proceso». 
En su impugnación, lógicamente, los recurrentes reconocen desde el principio la conexión de este recurso y el interpuesto contra el art. 16.1 LOTC, en la redacción dada al mismo por la Ley Orgánica 6/2007, de 24 de mayo, señalando que la reforma del Reglamento es consecuencia de la voluntad de aplicar, por parte de la mayoría del Senado, lo dispuesto en aquella. En coherencia con ello, los argumentos jurídicos que se utilizan aquí son sustancialmente iguales a los manejados en el anterior.

A su modo de ver, la reforma reglamentaria «confirma, completa y agrava» la inconstitucionalidad denunciada respecto a la reforma de la LOTC. Alegan que «la versión final del nuevo art. 184.7 RS cierra las puertas a que, junto a los candidatos propuestos por las Asambleas autonómicas, los senadores o los grupos parlamentarios del Senado puedan formular propuestas alternativas de candidatos, así como que la Cámara Alta pueda decidir finalmente sobre la capacidad, los requisitos y el perfil de los candidatos propuestos, respecto a los cuales ni siquiera podría decidir libremente su aceptación o rechazo».

Esta última limitación se deduce de la comparación del texto de la reforma inicialmente presentado, que contemplaba la posibilidad de elevar al Pleno otros candidatos «si no se hubiesen presentado suficientes o éstos no reuniesen, a juicio de la Comisión de Nombramientos, los requisitos legalmente exigidos, con el texto finalmente aprobado, que únicamente prevé esta posibilidad en el primero de los anteriores supuestos». Por ello, consideran que el Senado puede ver bloqueada su función constitucional de propuesta de Magistrados.

El TC, de acuerdo con la doctrina sentada en la Sentencia anterior, rechaza las tachas de inconstitucionalidad ya desechadas en ella. Así, por remisión a los fundamentos jurídicos 15 y 16 de aquel pronunciamiento descarta la vulneración de los arts. 72.1 y 165 CE. Lo mismo sucede en lo relativo a las diversas infracciones constitucionales relacionadas con la posición institucional del Senado, desestimados en el fundamento jurídico 17 del mismo. Finalmente también, e igualmente por remisión a la STC 49/2008, rechaza las tachas de inconstitucionalidad relacionadas con las facultades y el estatuto de los Senadores (arts. 67.2, 23.2 y, por extensión, art. 23.1 CE), dado que las mismas se resolvieron mediante la doctrina sentada en ese mismo fundamento jurídico.

También rechaza el Tribunal las pretensiones de los recurrentes referidas específicamente al nuevo apartado 7 del artículo 184 del Reglamento del Senado.

En cuanto a la primera objeción planteada —el hecho de que el citado precepto estaría impidiendo al Senado descartar candidatos presentados por los Parlamentos autonómicos que no reúnan los requisitos constitucional y legalmente establecidos para ser nombrados Magistrados del Tribunal Constitucional—, el TC entiende que no puede ser atendida. Tras repasar el régimen ju- 
rídico de este procedimiento destaca que en esta concreción reglamentaria del artículo 16.1 LOTC la presentación de candidatos a Magistrados se formula como una posibilidad o facultad de las Cámaras autonómicas. A su modo de ver, «nada ha de reprocharse a esta previsión procedimental, la cual tiene como finalidad hacer posible, en el sentido derivado de lo dispuesto en el art. 16.1 LOTC, la intervención de los Parlamentos autonómicos en la elección de los Magistrados del Tribunal Constitucional $\aleph^{30}$.

Con esta visión del asunto, el TC sortea nuevamente un problema al que hacíamos referencia más arriba: la contradicción evidente entre los términos imperativos en los que se expresa el artículo 16.1 LOTC y el planteamiento de la participación autonómica como una posibilidad por parte del precepto reglamentario ahora estudiado. La compatibilidad entre ambos preceptos ya había sido afirmada en la STC 49/2008, según hemos señalado anteriormente. En ella se establecía que, pese a tratarse de un supuesto excepcional, podría ocurrir que el sistema de elección de Magistrados previsto con carácter general por la LOTC no se viera culminado, por lo que el Senado se encontraba legitimado para prever fórmulas que le permitieran cumplir con su función constitucional en esos casos. De ahí podría deducirse - aunque no sin dificultad- que sería factible — entre otras cosas - que las Comunidades Autónomas, o alguna de ellas, se abstuvieran de presentar candidaturas.

Seguidamente, la argumentación del Tribunal se dirige a demostrar el control por parte del Senado de todo el proceso hasta el momento de la realización de la propuesta final de la Cámara alta. En primer lugar, en lo que se refiere al cumplimiento de los requisitos constitucionales por parte de los candidatos presentados por las Asambleas de las Comunidades Autónomas ${ }^{31}$. Aunque a éstas les corresponde la carga de acreditar que dichos requisitos se cumplen, la Mesa de la Cámara podrá decidir sobre la inadmisión de las candidaturas presentadas, si a su juicio, tales condiciones no se dan en alguno de los propuestos.

Por supuesto — advierte el TC — el hecho de que se supere esta primera fase de la propuesta no garantiza en absoluto la elección en la segunda y definitiva fase del proceso. La Comisión de Nombramientos del Senado, una vez formado su criterio acerca de la concurrencia en los candidatos de los requisitos necesarios para su designación como Magistrados, eleva, en su caso, al Pleno de la Cámara una propuesta con tantos candidatos como puestos a cubrir. Se trata — señala el Tribunal- «de una previsión procedimental interna en orden al cumplimiento de la función asignada por el art. 159.1 CE, la cual, evidentemente, no compe-

\footnotetext{
${ }^{30}$ F. J. 5.

31 F. J. 5.
} 
le al Pleno a aceptar la propuesta formulada, ya que este último órgano expresa, mediante la requerida votación, su propio juicio sobre los candidatos propuestos por la Comisión de Nombramientos» ${ }^{32}$.

En tercer lugar, el Tribunal recuerda que la facultad atribuida a la Comisión de Nombramientos del Senado para incluir candidatos distintos de los inicialmente propuestos, «responde a la necesidad de establecer una cláusula de cierre aplicable para el caso de que el sistema ordinario de elección, derivado de lo dispuesto en el art. 16.1 LOTC, no permitiera al Senado ejercer, conforme al art. 159.1 CE, su facultad de designación, cumpliendo de esa forma con su función constitucional $»^{33}$.

Finalmente, para que los candidatos propuestos sean definitivamente elegidos por la Cámara, se requiere «la obtención de la mayoría constitucionalmente requerida en la votación plenaria, votación en la cual, en coherencia con la prohibición constitucional de mandato imperativo derivada del art. $23 \mathrm{CE}$, se expresa la libre facultad de la que han de gozar los Senadores para elegir a los Magistrados del Tribunal Constitucional, a fin de poner así término a un procedimiento en cuya fase inicial se ha previsto la participación autonómica» ${ }^{34}$.

Tras todas estas consideraciones previas, el Tribunal llega al núcleo de los problemas planteados en la demanda ${ }^{35}$ : «la interpretación que haya de atribuirse a dicho inciso relativo a la falta de candidatos suficientes de entre los que hubieran debido ser presentados por las Asambleas Legislativas Autonómicas, supuesto que habilitaría al Senado, de acuerdo con el propio art. 184.7 RS, a tomar en consideración otras candidaturas distintas surgidas en su propio seno, a fin de evitar la paralización del proceso de designación». Dicho en otros términos, la cuestión es «si la Cámara, en realidad, es efectivamente libre para no aceptar a los candidatos propuestos por los Parlamentos autonómicos, pues es obvio que si la Cámara sólo tuviera una capacidad de rechazo, reactiva, frente a las propuestas autonómicas, su libertad de elección sólo habría quedado asegurada con el sacrificio de su obligación de designar cuatro Magistrados».

Y el TC aborda el análisis de esta cuestión avisando desde el principio que el precepto presenta ciertas dificultades: «es necesario apurar todas las posibilidades de interpretar los preceptos de conformidad con la Constitución y declarar tan sólo la derogación de aquellos cuya incompatibilidad con ella resulte indudable por ser imposible llevar a cabo dicha interpretación (por todas, STC 176/1999,

\footnotetext{
32 F. J. 6.

33 F. J. 7.

${ }^{34}$ F. J. 7.

${ }^{35}$ V. F. J. 8.
} 
FJ3)». Pero, en este caso, considera que no estamos «ante un supuesto en el que exista un conflicto evidente e insalvable entre el precepto reglamentario impugnado y las normas o principios constitucionales que integran su parámetro de control, señaladamente, el art. 159.2 CE».

Para empezar, entiende el Tribunal que la valoración respecto a si las candidaturas presentadas son o no suficientes corresponde apreciarla en exclusiva al Senado. Y aquí, considera que la Cámara es completamente libre para realizar el juicio de idoneidad que le merezcan las distintas candidaturas.

En cuanto a qué ha de considerarse como candidatura «suficiente», coincide con la interpretación planteada por la representación procesal del Senado y el Abogado del Estado. Frente a una posible interpretación literal o meramente numérica, la mayoría del Tribunal entiende que cabe también una interpretación cualitativa. En definitiva, las candidaturas serán «insuficientes» no sólo si así lo son numéricamente, sino también en los casos en los que no reúnan los requisitos constitucionalmente exigidos o en los que, incluso cumpliendo con estos requisitos, no sean merecedores de la confianza institucional de la Cámara ${ }^{36}$. Porque «en coherencia con la libertad última de la que goza la Cámara en relación con el juicio de idoneidad que le merezcan las distintas candidaturas, tampoco puede descartarse que sean los Senadores, en el acto final de elección por el Pleno de la Cámara, los que, libremente y con voto secreto dentro de las funciones senatoriales que personalmente les corresponden, decidan, mediante la mayoría reforzada constitucionalmente exigida, sobre la aceptación o, por el contrario, rechacen constituir dicha mayoría, respecto a todos o alguno de los candidatos seleccionados por la Comisión de Nombramientos de entre los previamente presentados en plazo por las Asambleas Legislativas de las Comunidades Autónomas, lo que igualmente habría de conducir a una nueva selección de candidatos por la Comisión de Nombramientos para someterla al Pleno, esta vez proponiendo candidaturas surgidas del propio seno de la Cámara» ${ }^{37}$.

Por otra parte, el principio de conservación de la norma impediría para el TC una interpretación de acuerdo con un "presunto tenor literal» de la expresión «candidaturas suficientes». Y ello, ni siquiera cuando la «voluntas legislatoris» parece apoyar tal interpretación. Porque el Tribunal no se considera vinculado por una interpretación basada en el debate parlamentario que tuvo lugar en el proceso de elaboración y aprobación de la norma enjuiciada, máxime en un supuesto "como el presente en el que la misma se contrapondría con un entendimiento del precepto que lo hace conforme con las previsiones constituciona-

\footnotetext{
36 F. J. 9.

37 F. J. 9.
} 
les, entendimiento que, por esa razón, ha de prevalecer, pues la interpretación aquí expuesta es la que, de acuerdo con un espíritu integrador y sistemático, resulta más razonable y es, además, conforme con la doctrina establecida en la STC 49/2008».

Esta es en opinión de nuestro Alto Tribunal la interpretación conforme a la Constitución del precepto controvertido, porque, con ella, se evita el riesgo de paralización del proceso de designación de Magistrados, y hace posible que el «Senado pueda velar por el ejercicio constitucionalmente correcto de su función» ${ }^{38}$.

\subsubsection{Los votos particulares}

Resaltamos en esta ocasión alguna de las cuestiones que se ponen de manifiesto en los tres votos particulares formulados a esta Sentencia, pues nos ayudarán a presentar nuestra propia posición respecto a la misma. También en este caso se producen continuas remisiones a lo establecido en la STC 49/2008. Aquí trataremos de ceñirnos principalmente a los argumentos referidos específicamente a la defensa de la inconstitucionalidad del artículo 184.7 RS, en contra de lo defendido por la mayoría del TC.

Para el Magistrado Delgado Barrio, el hecho de que el citado apartado se dictara "para ajustarlo» a la nueva redacción del art. 16 LOTC implica que "aquél queda afectado por la misma inconstitucionalidad que vicia éste».

Sólo de acuerdo con la interpretación de la mayoría resulta posible que el Senado elija los Magistrados del Tribunal Constitucional no entre los presentados por las Comunidades Autónomas, sino fuera de los que han sido propuestos. Pero, a su modo de ver, «esta interpretación resulta perfectamente contraria al inequívoco sentido normativo de la norma impugnada, que deriva inexorablemente de la finalidad, expresamente declarada, del art. 184.7 RS, de su tenor literal y del ostensible entendimiento que luce muy decisivamente en el debate

${ }^{38}$ F. J. 10. Al final de este fundamento jurídico el TC declara que «En mérito de lo expuesto, y así interpretado el precepto impugnado podemos apreciar que el Reglamento del Senado, cuyo contenido propio es el de regular, con sujeción a la Constitución, su propia organización y funcionamiento rigiendo el ejercicio de las competencias que corresponden a la Cámara, ha velado adecuadamente por el ejercicio constitucionalmente correcto de esta concreta función de designación atribuida a la Cámara, evitando tanto el riesgo de bloqueo en su ejercicio como que la misma pueda quedar vacía materialmente de contenido». Pero, a la vista de los trabajos parlamentarios, parece que el que ha velado por que el Senado pueda cumplir de forma «constitucionalmente correcta» con su función ha sido el TC. 
parlamentario que dio vida al precepto aquí impugnado». Respecto a este último, recuerda que la defensa de la enmienda que llevó a la redacción actual del precepto señalaba como objetivo el de «acotar los supuestos en los que la Comisión de Nombramientos puede proponer otros candidatos a la consideración del Pleno de la Cámara y reducirlos únicamente a uno, y es que no se hayan presentado candidaturas suficientes para cubrir el cupo que le corresponde al Senado en la designación de Magistrados» ${ }^{39}$.

El Tribunal —continúa este Magistrado- presenta en esta Sentencia una manifiesta interpretación contra legem no cubierta por el principio de conservación de las normas, pues este no alcanza ««a ignorar o desfigurar el sentido de los enunciados legales meridianos» (SSTC 22/1985, de 15 de febrero, FJ 5; 222/1992, de 11 de diciembre, FJ 2; y 341/1993, de 18 de noviembre)».

Delgado Barrio considera, en definitiva, que estamos ante un exceso de jurisdicción, por el que el TC ejerce la función de «legislador positivo" que desborda amplia y ostensiblemente el cometido institucional que la Constitución le atribuye.

El Magistrado Rodríguez-Zapata señala respecto al artículo aquí enjuiciado, en primer lugar, que se encuentra viciado de inconstitucionalidad por razones formales, ya que «en materia de elección de los miembros de este Tribunal, dicho Reglamento no se puede subordinar a nuestra Ley orgánica, ni a ninguna otra». Sin embargo, con la doctrina de la STC 49/2008 en la mano parece deducirse — según su visión de la misma— «que el segundo párrafo del artículo 16.1 LOTC está situado en una posición de «jerarquía superior» respecto al propio Reglamento de la Cámara». De ahí proceden, mantiene más adelante, las dificultades del Tribunal para sostener la regularidad constitucional de la norma.

También lo considera inconstitucional por razones materiales, pues, en su opinión, el Reglamento «se ha de limitar única y exclusivamente al desarrollo procesal de la regulación sustantiva del art. 159.1 CE».

Para terminar, realiza un último reproche a la mayoría. Cuando la Sentencia —en el FJ 5- juzga «no imposible» que sean los grupos parlamentarios del Senado los que presenten los candidatos autonómicos, aunque considera «más lógico", por razones que no explica, que la propuesta se haga directamente desde las Asambleas Legislativas de las Comunidades Autónomas, (...) dibuja, con un detalle sorprendente (FJ 5, penúltimo párrafo o FJ 8, segundo párrafo) un procedimiento de elección tan complicado que podría vulnerar la autonomía fun-

39 Se remite a lo establecido en la Comisión de Reglamento del Senado, 13 de noviembre de 2007. 
cional de la Cámara Alta y los poderes de interpretación y de suplir lagunas de reglamento de su Presidente».

El Magistrado Conde recuerda aquí que en el voto particular que formuló a la STC 49/2008, defendió que era precisamente el Reglamento de la Cámara y no la LOTC - el que puede regular la participación autonómica, pero «según los términos en que lo haga». Y, en principio, no observa ninguna dificultad en que éste pueda abrir una vía de colaboración de las Comunidades Autónomas, o de sus Asambleas Legislativas en la selección de candidatos; pero siempre que ello no se haga en términos que condicionen, anulándola, la plena libertad del Senado para elegir en todo el círculo de juristas del art. 159.2 CE, pues tal condicionamiento implica una abdicación, al menos parcial, de la misión que la Constitución encomienda al Senado. Señala que «las potestades de los órganos constitucionales no son disponibles por sus titulares, y suponen deberes constitucionales que deben ser cumplidos en los términos que la Constitución ha previsto".

La Sentencia de la que ahora se aparta no se limita, a su modo de ver, a seguir la línea discursiva de la Sentencia anterior, sino que da un paso más. En aquel pronunciamiento se abría paso a la posibilidad del Senado de optar por candidatos de exclusiva propuesta senatorial, en el caso de que no aceptara a ninguno de los candidatos propuestos por las Comunidades Autónomas, como «mera posibilidad que no mandato condicionante de una reserva sobre la constitucionalidad del art. 16.1 LOTC». Tal posibilidad se convierte ahora —en su opinión — «en clave de la necesidad de salvaguardar la «libertad institucional, insuprimible, del Senado» que «no pude llevar a la imposibilidad de cumplir con su obligación constitucional de designar Magistrados del Tribunal Constitucional» (FJ 9, párrafo 8)».

La citada salvaguarda — advierte - se erige en pauta obligada para una interpretación conforme del art. 184.7 RS. Pero esa interpretación conforme resulta, en su opinión, jurídicamente inaceptable, por exceder notoriamente de los límites que para ella se fijan en la propia doctrina del TC, «haciéndole decir al precepto lo que en modo alguno dice, y sustituyéndolo en realidad por un precepto distinto".

Conde rechaza lo que considera una manipulación del sentido del precepto impugnado. En la Sentencia (FJ 9, párrafo $2^{\circ}$ in fine) se afirma que «el nuevo procedimiento de selección de candidatos a Magistrados del Tribunal Constitucional no puede abocar indefectiblemente a aceptar en todo caso a los propuestos por los Parlamentos autonómicos». Y eso es, en su opinión, "precisamente lo que resulta del conjunto normativo integrado por el art. 16.1 LOTC y 184.7 RS, y de ahí su inconstitucionalidad». 
Un importante apoyo de una comprensión tal del precepto es, según este Magistrado, la voluntas legislatoris que se desprende de los trabajos parlamentarios $^{40}$. En este caso — señala - ha de tener un peso mayor que en otros, por darse aquí la coincidencia entre autor y receptor de la norma. Además — advierte«su desconocimiento incluso puede incurrir en el riesgo de falta de respeto por este Tribunal a la autonomía de otro órgano constitucional como es el Senado».

Pone de manifiesto, asimismo, la contradicción entre los términos del art. 16. 1 LOTC, según el cual, parece que las elección de los candidatos ha de tener su origen exclusivo en las propuestas autonómicas y los términos del art. 184.7 RS que, en interpretación del TC abre las puertas a la elección de candidatos ajenos a tales propuestas: « $\mathrm{Si}$, en efecto, el Reglamento dijese una cosa tal, el Reglamento vendría a negar lo que dice la LOTC, cuya constitucionalidad, no se olvide, hemos salvado sin reserva alguna».

Todo ello se debe, según su visión del asunto, a que «el argumento se desenfoca voluntaristamente en su inicio, cuando lo que debe ser simple constatación de un hecho objetivo: existencia o no de número suficiente de candidatos propuestos, se transforma en un juicio de valor del Senado sobre la suficiencia de las candidaturas".

Para Conde «se revela ahí la resistencia a aceptar que el Senado quede vinculado por las propuestas de los legislativos autonómicos, pese a que la constitucionalidad de esa vinculación [...] se aceptó en la STC 49/2008 de constante cita, en contra de mi criterio. Sobre esa base inicial se asienta el reconocimiento al Senado de la apreciación de la idoneidad para el cargo de los propuestos, y la afirmación (un paso más) de que «la Cámara es plenamente libre en relación con

40 Señala que «en un momento de la elaboración parlamentaria del que ha venido a ser el precepto impugnado en el actual recurso, el inciso «si no se hubieran presentado en plazo candidaturas suficientes», tenía el añadido de "o los candidatos presentados no reunieran, a juicio de la Comisión, los requisitos exigidos». Mas dicho añadido fue objeto de una enmienda de supresión, que se justificaba en la necesidad de introducir mayor claridad en la regulación, con la pretensión, según se expone en el Diario de Sesiones de la Comisión de Reglamento del Senado de 13 de noviembre de 2007, de acotar los supuestos en los que la Comisión de Nombramientos puede proponer otros candidatos a la consideración del Pleno y reducirlos únicamente a uno; esto es, únicamente que no se hubieran presentado candidaturas suficientes en número por las Asambleas Legislativas de las Comunidades Autónomas. Tal enmienda se incorporó al texto de la reforma en el dictamen emitido por la Comisión de Reglamento del Senado de 13 de noviembre de 2007, dictamen aprobado por el Pleno del Senado en su sesión de 21 de noviembre de 2007».

Hace referencia también al Diario de Sesiones del Senado, de 21 de noviembre de 2007, pues en el debate parlamentario se afirma expresamente "se elimina el párrafo que podría llevar al equívoco de otorgar a la Comisión de Nombramientos una competencia sobre el juicio de idoneidad de los candidatos». 
el juicio de idoneidad que le merezcan las distintas candidaturas ante ella presentadas», porque «el nuevo procedimiento de selección de candidatos a Magistrados del Tribunal Constitucional no puede abocar indefectiblemente a aceptar en todo caso a los propuestos por los Parlamentos autonómicos».

La salida para este problema la ha encontrado el Tribunal, según su visión de las cosas, manteniendo «simultáneamente dos tesis en sí contradictorias: la de la constitucionalidad de los preceptos, y la del rechazo de la vinculación que con ellos se produce», lo que - considera - «es tanto como mantener una tesis y la contraria en diferentes momentos de un mismo discurso, que por principio, debe ser coherente en su conjunto».

Por todo ello, entiende que «la interpretación conforme que se propone no es tal, pues en el sentido normativo del precepto interpretado, no cabe encontrar el que la Sentencia le da, sino una recreación manipulativa del precepto, vedada a este Tribunal Constitucional $»^{41}$.

\subsubsection{Interpretación conjunta de ambas resoluciones}

Las dos Sentencias comentadas están condenadas a interpretarse de forma conjunta. A diferencia de lo mantenido por el Magistrado Vicente Conde en su voto particular, nos parece que hay una unidad de criterio entre ambas, de manera que, puede decirse, la segunda resolución es el corolario de la primera.

El citado Magistrado critica, no sin razón: si es constitucional la previsión contenida en el Reglamento del Senado, no lo es la contenida en la LOTC. Pero el TC ha sorteado — como ya hemos señalado anteriormente- este problema, imponiendo su propia interpretación de los preceptos enjuiciados. El artículo 16.1 LOTC parece prescribir que la elección de los Magistrados a proponer por el Senado ha de producirse necesariamente entre los candidatos presentados por las Asambleas Legislativas de las CCAA. Pero el Tribunal lo ha interpretado como una norma abierta a distintas posibilidades de regulación por parte del Reglamento del Senado. Éste, entonces, puede permitir que, en determinados supuestos, se prescinda de las propuestas autonómicas, si ello es necesario para salvaguardar el correcto ejercicio de su función constitucional.

El TC, por tanto, en la primera de las Sentencias enjuiciadas, salva de esta manera la constitucionalidad del art. 16.1 LOTC, prescindiendo de lo que parece desprenderse de su tenor literal. Así, ya desde esta primera decisión, trasla-

${ }^{41}$ V. la crítica que, en este sentido, realiza P. CRUZ VILLALÓN en «El Estado del Tribunal Constitucional», Claves de Razón Práctica núm. 191, 2009, pp. 4-12, pp. 11 y 12. 
da el problema sobre la constitucionalidad de la nueva regulación al Reglamento del Senado, pues es a esta Cámara a la que le corresponde velar, mediante una correcta regulación reglamentaria, por la función constitucional que le asigna el artículo $159 \mathrm{CE}$.

En este primer pronunciamiento, por tanto, las cosas — si hemos entendido bien al Tribunal— quedan así: la competencia para prever la participación autonómica en la elección de los Magistrados es del legislador, a través de la LOTC. Éste no debe vulnerar la autonomía de la Cámara Alta, de forma que, se entiende, la LOTC debe dejarle distintas posibilidades de regulación del ejercicio de su función constitucional, como efectivamente hace, según la visión del TC. Es, entonces, al Senado al que le corresponde «concretar» el sistema de elección de manera que esa función constitucional quede preservada. De no ser así, la regulación reglamentaria puede y debe ser declarada inconstitucional.

En la segunda decisión, el TC se pregunta si la regulación que, de facto, ha llevado a cabo el Senado es o no acorde a la Constitución. En su análisis, el Tribunal presenta al precepto reglamentario como una "concreción» del artículo 16.1 LOTC, lo cual resulta un tanto distorsionante desde el punto de vista de la autonomía parlamentaria, de acuerdo con lo que hemos mantenido anteriormente. No es de extrañar que se critique - por parte del Magistrado RodríguezZapata- la apariencia de subordinación del Reglamento a la LOTC que crea este modo de concebir la relación entre ambas normas.

A la regulación contenida en la Ley la denomina el Tribunal «sistema ordinario de elección». De manera que, parece ser, la previsión legal está "abierta», pero impone ciertas condiciones. En principio y, si todo va bien, la elección de los candidatos ha de producirse sobre la base de los presentados por las Asambleas Legislativas de las CCAA. Pero, si las cosas no van bien [es decir, en palabras del TC: «si, por ejemplo, el número de candidatos presentados es insuficiente, si (la Cámara) considera que los candidatos propuestos no cumplen los requisitos exigidos constitucionalmente, o si la elección de algunos de los Magistrados se frustra por no alcanzarse la mayoría requerida $»^{42}$ ), el Senado ha de tener la posibilidad de actuar de otra manera en defensa de la función constitucional que le ha sido asignada.

Llegados a este punto, el problema con el que nos encontramos es que la norma reglamentaria prevé que la Cámara alta podrá incluir en la propuesta que eleve al Pleno otros candidatos en el caso de que «no se hubieran presentado en plazo candidaturas suficientes». Pero para el TC el problema no es tal, pues considera que el precepto no puede entenderse en sentido literal, como sufi-

${ }^{42}$ STC 49/2008, F. J. 10. 
ciencia numérica, por impedirlo el principio de conservación de la norma. Porque, de hacerlo así, no pasaría el test de constitucionalidad, ya que no sería bastante para asegurar el cumplimiento de la función constitucional de la Cámara. Para que tal cumplimiento quede asegurado es necesario interpretar que no habrá candidaturas «suficientes» no sólo cuando no lo sean numéricamente, sino tampoco en los casos en los que no reúnan los requisitos constitucionalmente exigidos o en los que, incluso cumpliendo con estos requisitos, no sean merecedores de la confianza institucional de la Cámara.

En resumen, de acuerdo con la interpretación ofrecida por el Tribunal en ambas Sentencias habría un sistema ordinario de elección, previsto en el art. 16.1 LOTC y un sistema excepcional contenido en el apartado séptimo del artículo 187 RS, a través del cual se permitiría a la Cámara alta «escapar» del sistema común, si ello resulta necesario para salvaguardar su función Constitucional. Un diseño complicado destinado a evitar que la autonomía del Senado se vea perturbada, porque previamente se ha declarado constitucional la prescripción contenida en el art. 16.1 LOTC.

Ciertamente, la interpretación planteada por el TC en ambas Sentencias resulta tan forzada que cuesta reconocer los preceptos enjuiciados. No es de extrañar, por ello, que los Magistrados disidentes hayan puesto sobre la mesa la vieja polémica del Tribunal como legislador positivo y sus límites a la hora de llevar a cabo la interpretación conforme a la Constitución. Con ellas, como ha puesto de manifiesto la doctrina, el Tribunal «abunda en la línea de las «sentencias desestimatorias con fundamentación interpretativa» iniciada con la STC 247/2007, de 12 de abril, para el Estatuto valenciano» ${ }^{43}$. Efectivamente, son éstas sentencias materialmente interpretativas pero cuyo fallo no se remite a los correspondientes fundamentos jurídicos que fijan la interpretación constitucionalmente admisible. De esta manera, se crea una notable inseguridad jurídica, pero es necesario coincidir con aquellos que sostienen que lo más grave es que provocan «una cesura insuperable entre los fundamentos de la Sentencia y su parte dispositiva, con el riesgo de que ésta se constituya en un simple dictum» ${ }^{44}$.

En cuanto al fondo de la cuestión —ya lo anunciábamos al comentar la primera de las Sentencias-, el problema no se encuentra, a nuestro entender, en la presentación de candidatos por las Asambleas Legislativas de las CCAA. Tal participación autonómica nos parece no sólo deseable, sino también compatible con la Constitución. Nuestra crítica se centra, principalmente, en el hecho de que debe ser única y exclusivamente al Senado al que le corresponda prever esa

43 J. L. REQUEJO PAGÉS, REDC núm. 83, op. cit., pg. 212.

${ }^{44}$ Ídem nota anterior. 
participación en uso de su autonomía y no al legislador. Para salvar la constitucionalidad de la previsión contenida en la reforma de la Ley, el Tribunal presenta un panorama normativo complicado que no puede comprenderse con la mera atención a los preceptos enjuiciados, sino que obliga a tener presente el contenido de las dos resoluciones estudiadas. Y ello, según lo apuntado anteriormente, si es que otorgamos algún valor vinculante a la ratio decidendi. En ese caso, el primer llamado a tener en cuenta ese contenido sería el Senado que, en su interpretación de la norma, deberá prescindir de su propia voluntad expresada durante el proceso de elaboración de la norma y atender a las indicaciones marcadas por el TC como último y supremo intérprete de la Constitución. El horizonte se ensombrece aún más al constatar la desvirtuación del nuevo modelo de designación que ha tenido lugar en la práctica y cuyo origen se halla en la ausencia de acuerdo político entorno a esta reforma ${ }^{45}$.

Los pronunciamientos comentados dan así el visto bueno a una participación que puede considerarse conveniente y legítima. Pero, como se ha señalado por la doctrina, el argumento de la legitimidad del fin perseguido no puede justificar un medio contrario a la Constitución ${ }^{46}$.

\section{LA STC 49/2008 ANTE EL NUEVO APARTADO TERCERO DEL ARTÍCULO 16 LOTC: PRÓRROGA DEL CARGO DE PRESIDENTE}

Como anunciábamos al principio de este trabajo, el otro precepto de la reformada LOTC que ha sido impugnado es el contenido en el apartado tercero del artículo 16 LOTC, en el que se establece: «La designación para el cargo de Magistrado del Tribunal Constitucional se hará por nueve años, renovándose el Tribunal por terceras partes cada tres. A partir de ese momento se producirá la elección del Presidente y Vicepresidente de acuerdo con lo previsto en el artículo 9. Si el mandato de tres años para el que fueron designados como Presidente y Vicepresidente no coincidiera con la renovación del Tribunal Constitucional, tal mandato quedará prorrogado para que finalice en el momento en que dicha renovación se produzca y tomen posesión los nuevos Magistrados».

${ }^{45}$ A esta desvirtuación se refiere P. CRUZ VILLALÓN en su obra ya citada (pg. 10), al recordar la instrucción dada por el Partido Popular a todos sus miembros en los distintos parlamentos autonómicos de proponer como únicos candidatos a los dos propuestos inicialmente por aquél partido y los problemas que de esta práctica se derivan.

${ }^{46}$ J. L. REQUEJO PAGÉS, REDC núm. 83, op. cit., pg. 213. 


\subsection{Abstenciones y recusaciones}

La medida legal contenida en el mismo, ha levantado ampollas en el seno del propio TC. Prueba de ello es la carta dirigida por dos de sus Magistrados (Roberto García-Calvo y Jorge Rodríguez-Zapata) a la Presidenta el 22 de junio de 2007, en la que se exigía la dimisión en el cargo de la Presidenta y del Vicepresidente $^{47}$.

A partir de este momento y, en parte, como consecuencia de este escrito, tienen lugar una serie de abstenciones y recusaciones de ciertos Magistrados del TC que serían merecedoras por sí mismas de un comentario aparte, pero que aquí sólo daremos cuenta de ellos por la gran repercusión que han adquirido dentro del proceso principal que estamos analizando ${ }^{48}$.

Mediante sendos escritos fechados el 5 de septiembre de 2007 la Presidenta del Tribunal, Doña María Emilia Casas Baamonde, y el Vicepresidente, Don Guillermo Jiménez Sánchez, manifestaron al Pleno su voluntad de abstenerse del conocimiento de dicho recurso. Con idéntico contenido, tras invocar los arts. 80 LOTC y 217,219 y 221 LOPJ, ambos escritos citan el art. $219.10^{\circ}$ LOPJ como causa de abstención, "dado que podría suscitarse apariencia de pérdida de imparcialidad a la vista de que uno de los preceptos recurridos se refiere al mandato del Presidente (Vicepresidente) del Tribunal Constitucional». Las abstenciones fueron estimadas justificadas por la mayoría del Pleno del TC en el Auto 387/2007, de 16 de octubre de $2007^{49}$ (el mismo día que fue admitido a trámite el recurso de inconstitucionalidad mediante providencia).

El día 19 de octubre de 2007 fue presentado en el registro del Tribunal escrito del Abogado General del Estado formulando, en nombre del Gobierno de la Nación, la recusación de los Magistrados don Roberto García-Calvo y Montiel y don Jorge Rodríguez-Zapata Pérez por concurrir las causas de recusación previstas en los arts. 219.10, $219.13^{\mathrm{a}}$ y $219.16^{\mathrm{a}}$ LOPJ. Como prueba docu-

\footnotetext{
$47 \mathrm{Su}$ texto puede consultarse en:

http://www.elpais.com/articulo/espana/profunda/discrepancia/reforma/elpepuesp/20070924elpepinac 5/Tes.

${ }_{48}$ Un comentario de estas recusaciones puede encontrarse en L. E. DELGADO DEL RINCÓN, «La recusación de los Magistrados del Tribunal Constitucional», en Revista Española de Derecho Constitucional, núm. 82, 2008, pp. 347-393.

V. también, J. L. REQUEJO PAGÉS, REDC, núm. 83, op. cit., pp. 209-211.

49 Formularon voto particular concurrente los Magistrados Dña. Elisa Pérez Vera, don Pascual Sala Sánchez, don Manuel Aragón Reyes y don Pablo Pérez Tremps, así como, por su parte, Don Eugeni Gay Montalvo.
} 
mental se pide el recibimiento, precisamente, de la copia certificada de la carta dirigida por los Magistrados Roberto García-Calvo y Montiel y don Jorge Rodríguez-Zapata Pérez a la Presidenta del Tribunal Constitucional el 22 de junio de 2007, así como del Acta de la reunión del plenario del Tribunal Constitucional celebrada el 4 de julio de 2007, en la que se entró en el estudio y se adoptó acuerdo en relación con la carta anterior.

Por su parte, el día 26 de octubre de 2007 los recurrentes presentaron escrito de recusación de los Magistrados don Pascual Sala Sánchez, don Pablo Pérez Tremps y don Manuel Aragón Reyes, por concurrir las causas de recusación con-

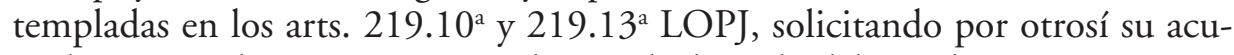
mulación con la recusación instada por el Abogado del Estado.

Es claro que las citadas recusaciones ponían al TC en una situación de bloqueo, pues le impedían alcanzar el quórum necesario para adoptar decisiones exigido por el art. 14 LOTC en la resolución de los incidentes de recusación, con la consiguiente parálisis respecto al proceso principal. Sin embargo, el Tribunal, apoyándose en lo dispuesto en el art. 4 LOTC (que prevé que «El Tribunal delimitará el ámbito de su jurisdicción y adoptará cuantas medidas sean necesarias para preservarla») decide mayoritariamente resolver esta situación despegándose de la legislación procesal declarada supletoria por el art. 80 LOTC (LOPJ, en este caso), por considerarla inaplicable al supuesto planteado ${ }^{50}$. Así, no accede a la acumulación de ambas recusaciones, resuelve primeramente la última de ellas (con la participación de todos los Magistrados afectados por la recusación), inadmitiéndola a trámite por Auto 443/2007, de 27 de noviembre $^{51}$ y, en un segundo Auto (ATC 81/2008, de 12 de marzo), resuelve la primera petición, estimando las recusaciones solicitadas en ella ${ }^{52}$.

En virtud de este último Auto y de las abstenciones de la Presidenta y del Vicepresidente la reforma de la LOTC fue juzgada por un Pleno de ocho Magistrados, declarándose constitucional por el voto favorable de cinco de ellos.

50 V. F. J. 3.

51 Votos particulares de D. Roberto García-Calvo, D. Jorge Rodríguez-Zapata y D. Ramón Rodríguez Arrivas.

${ }^{52}$ Formularon votos particulares los Magistrados, Javier Delgado Barrio y Ramón Rodríguez Arribas.

La practicada por el TC no hubiera sido la única solución factible. Otra posibilidad, como apunta A. DE LA OLIVA («Una salida al «bloqueo» del Tribunal Constitucional», diario $A B C$, edición del día 26 de noviembre de 2007), sería la de haber resuelto cada recusación de forma individual con exclusión, en cada caso, del Magistrado afectado por ella. Con esta solución se aportaría una mayor apariencia de imparcialidad, en tanto que la vía utilizada por el TC presenta la ventaja de una mayor economía procesal. 
Como ha sido puesto de manifiesto, «este dato constituye, por sí sólo, la peor crítica que cabe hacer a la STC 49/2008 "53.

\subsection{La cuestión de fondo}

Aunque los recurrentes se refieren no sólo a la prórroga del cargo del Presidente sino también a la del Vicepresidente calificándola como «ilógica» ${ }^{54}$, el TC, con razón, entiende limitada la impugnación a la prórroga del mandato presidencial, en la medida en que el art. 160 CE sólo se refiere al Presidente del Tribunal y no al Vicepresidente ${ }^{55}$.

En el recurso se recuerda que dicho artículo de la Constitución establece que «el Presidente del Tribunal Constitucional será nombrado entre sus miembros por el Rey, a propuesta del mismo Tribunal en Pleno y por un período de tres años», es decir, «un tiempo delimitado y conceptualmente unívoco». Por ello entienden que la ley orgánica podría admitir una renovación, previa elección entre los miembros y nombramiento por el Rey, pero lo que no cabe es una prórroga automática inconstitucional del mandato. Consideran además que los miembros que compongan en cada momento el Tribunal deben elegir un Presidente cada tres años. Y el legislador no puede sustraer al Pleno del Tribunal esa competencia constitucional, como no podría tampoco, por ejemplo, limitarla fraccionando los tiempos de mandato o restringiendo el número o nombre de los elegibles $^{56}$.

Frente a lo argumentado por los recurrentes, el TC se centra, fundamentalmente, en las cuestiones que pasamos a exponer. La primera de ellas, que la regulación de la Presidencia que lleva a cabo el art. 160 CE no tiene carácter exhaustivo. No se definen ni sus funciones, ni sus concretas competencias, ni el modo de ejercerlas. Por ello, ha de entenderse que no se impide la intervención de la LOTC para desarrollarla y concretarla, como sucede de hecho. Por tanto, el interés se centra en determinar si el legislador ha respetado o no los límites constitucionales a los que está sometido en este ámbito. Para dar respuesta a esta pregunta, el TC vuelve a proponer aquí una interpretación desde el «conjunto de

53 V. J. L. REQUEJO PAGÉS, REDC, núm. 83, op. cit., pg. 211. Señala este autor que la citada Sentencia «con su exigua mayoría y su esforzada solución no parece la mejor respuesta a una reforma tan polémica, en el fondo y en las formas, como la de la Ley Orgánica 6/2007».

54 V. el Antecedente primero, apartado c).

55 V. F. J. 1, último párrafo.

${ }^{56} \mathrm{~V}$. antecedente primero, letra c). 
normas y principios constitucionales que se proyectan sobre la Presidencia y sobre el propio Tribunal Constitucional ${ }^{57}$.

Por un lado — se dice—, el art. 16 LOTC distingue claramente la elección del Presidente de la prórroga de su mandato. Respecto a la primera, el apartado tercero de ese artículo introduce una novedad que no ha sido impugnada, pero que - a juicio del Tribunal - resulta muy importante para interpretar la finalidad de la norma. Se trata del momento en que dicha elección debe producirse, aspecto que hasta el momento no se había regulado expresamente y que ahora queda claro que debe tener lugar después de cada renovación parcial del Tribunal. Tal extremo, considera el Tribunal, obedece a la propia lógica constitucional, ya que tanto el art. $160 \mathrm{CE}$ como el art. 159.3 CE prevén el mismo plazo temporal (3 años) para ambas figuras.

El Tribunal Constitucional recuerda que no se trata de una reelección, sino de una prórroga automática del mandato presidencial vigente que sólo se produce si el mandato para el que fue designado el Presidente «no coincidiera con la renovación del Tribunal». Lo que se pretende con ello es prorrogar su mandato hasta que el Tribunal renovado esté en condiciones de proceder a la elección de la nueva Presidencia, con participación ya de los nuevos Magistrados, de acuerdo con lo dispuesto en el art. 9 LOTC.

La finalidad perseguida por la reforma, por tanto, no puede considerarse ni arbitraria ni vulneradora de ningún otro precepto constitucional, pues lo que pretende es armonizar, por uno de los muchos medios posibles, diversos aspectos del modelo organizativo del TC. Asimismo, puede considerarse constitucionalmente legítima. Y ello se deduce, entre otras cosas, de su repercusión en el funcionamiento y en el modelo organizativo del Tribunal Constitucional, en tanto que permite que éste continúe ejerciendo sus competencias con normalidad hasta que se produzca su renovación. $\mathrm{Al}$ mismo tiempo $-\mathrm{y}$ sin trasladar, por ello, al TC el concepto de representación política - el TC considera que la previsión legal «refuerza la figura de la Presidencia tanto antes como después de la renovación, puesto que garantiza que el colegio de Magistrados sea presidido en todo momento por un miembro del Tribunal elegido con concurso de todos sus integrantes ${ }^{58}$.

Una vez fuera de dudas la legitimidad constitucional de la finalidad perseguida, el TC entra a valorar la prórroga legal del mandato presidencial como instrumento utilizado legislativamente para alcanzarla. Lo primero que se aclara es que no resulta asimilable a un fraccionamiento de tal mandato ni a

\footnotetext{
57 F. J. 19.

58 F. J. 20, último párrafo.
} 
una restricción del número o del nombre de los candidatos a ocupar la Presidencia. También se rechaza que vulnere el art. $160 \mathrm{CE}$, ya que lo que se prevé es una prórroga del mandato presidencial vigente y no un nuevo nombramiento ${ }^{59}$.

Pero, en definitiva, el TC destaca que las reticencias de los recurrentes se centran en el carácter automático y, por tanto, sin intervención del Pleno, de la prórroga $^{60}$. Frente a esta objeción, el Tribunal defiende la constitucionalidad de la norma impugnada con alusiones a la experiencia pasada del Tribunal Constitucional en situaciones similares a las previstas legalmente ${ }^{61} \mathrm{y}$, sobre todo, negando la sustracción legal de una competencia constitucional del Pleno, pues no es la competencia para prorrogar, sino para elegir la que el artículo $160 \mathrm{CE}$ le otorga $^{62}$.

En este caso, coincidimos con lo señalado por el TC. Y a sus argumentos habría que añadir que la LOTC sí es aquí la norma idónea para llevar a cabo esta regulación que tiene que ver con la organización del TC. Porque, ciertamente, la prorrogatio no sustituye a la elección, sino que es un instrumento jurídico creado para permitir la continuidad y asegurar el buen funcionamiento del órgano hasta el momento en que aquélla pueda producirse nuevamente. La LOTC es la destinataria de la reserva legal contenida en el artículo $165 \mathrm{CE}$ para la regulación del funcionamiento del Tribunal Constitucional. Por tanto, a ella le correspon-

59 En el segundo párrafo del F. J. 21, el Tribunal señala que temporalidad del mandato y prórroga no son incompatibles, como lo demuestra la misma prórroga legal del mandato de los Magistrados prevista en el art. 17.2 LOTC. Igualmente, se ponen ejemplos de la práctica del Tribunal en los que, por el contrario, se produce un acortamiento del mandato.

${ }^{60}$ Esta misma objeción es compartida por el Magistrado Javier Delgado Barrio en su voto particular.

${ }^{61}$ J. L. REQUEJO PAGÉS (REDC núm. 83, op. cit., pg. 215) recuerda que «no es enteramente cierto que la Ley haya acogido la práctica observada por el Tribunal en el pasado. Ha habido casos en los que el Presidente cesó como Magistrado antes de concluir los tres años de su presidencia (así, Sres. Rodríguez-Piñero, Cruz Villalón y Jiménez de Parga); otros en los que el Pleno prorrogó tácitamente la presidencia de quien ya debía ser renovado como Magistrado (así, Sr. Rodríguez Bereijo). Y, por último, el caso de quien, agotada su presidencia y continuando como Magistrado por derecho propio, es decir, sin prorogatio (supuesto, por tanto, en junio de 2007, de la Sra. Casas Baamonde), fue nombrado Presidente por segunda vez (así, Sres. GarcíaPelayo y Tomás y Valiente). Si a la práctica nos atenemos, por tanto, más bien debiera concluirse que lo propio hubiera sido disponer que, agotada la presidencia de quien continúa como Magistrado por derecho, debe elegirse una nueva presidencia, y que, terminado el mandato presidencial de quien también ha cumplido con el plazo de nueve años de su magistratura, su prórroga como Magistrado implica su prorogatio como Presidente».

62 V. F. J. 21.

(C) UNED. Revista de Derecho Político 
de la ordenación de todos aquellos aspectos no previstos por la Constitución y que se consideren necesarios para hacer posible el correcto ejercicio de sus funciones. De hecho, en ella, y no en la Constitución, ya se prevé - como recuerda el TC en el F. J. 21 de esta Sentencia- la prorrogatio de los Magistrados del $\mathrm{TC}^{63}$.

Respecto a esta figura, la doctrina ya había puesto de manifiesto hace tiempo la necesidad de aclarar si debía aplicarse también a las funciones de Presidente y Vicepresidente, una vez expirado el plazo de su mandato como Magis$\operatorname{trados}^{64}$. La aclaración podría haber venido de la mano del Reglamento de Organización y Personal del TC. Pero también es perfectamente admisible (de acuerdo con la remisión contenida en el artículo 165 CE ya aludida) que esta aclaración se contenga en la LOTC ${ }^{65}$. Porque, guste o no guste, hay que admitir que la prórroga del mandato del Presidente y del Vicepresidente es una medida tendente a ordenar el funcionamiento del órgano que trata de garantizar que todos los Magistrados se sientan —en la medida de lo posible - repre-

${ }^{63}$ En el artículo 17.2.: "Los Magistrados del Tribunal Constitucional continuarán en el ejercicio de sus funciones hasta que hayan tomado posesión quienes hubieren de sucederles».

La figura de la prorrogatio es, por otro lado, muy común como solución de continuidad institucional en el Derecho propio de los órganos constitucionales (y no sólo en el parlamentario). Un interesante estudio sobre el sentido de esta institución puede encontrarse, aunque referido al Gobierno, en A. GONZÁLEZ ALONSO, «Los Gobiernos cesante o en funciones en el ordenamiento constitucional español», Asamblea, Revista Parlamentaria de la Asamblea de Madrid, núm. 12, en especial págs. 221, 247-248.

${ }^{64}$ V. J. LOZANO MIRALLES / A. SACCOMANNO, El Tribunal Constitucional. Composición y principios jurídico - organizativos (el aspecto funcional), Tirant Lo Blanch, Valencia 2000, pg. 58. Es cierto, sin embargo, que estos autores consideran conveniente dejar en manos del TC la solución a esos problemas a través de su Reglamento de Organización. No les parecía adecuado que tales reglas se contuvieran en la LOTC, porque significaría encorsetar en exceso al TC.

En P. RODRÍGUEZ- PATRÓN (op. cit., pg. 151), hemos defendido la necesidad de que se aclarara ese punto en el Reglamento del Tribunal, pero por el mero hecho de que tal previsión no se contenía en la LOTC. Nada que objetar, sin embargo, de acuerdo con las razones expuestas en el texto, a la introducción de la figura en la reforma de la LOTC.

M. ARAGÓN REYES (op. cit., pg. 16) recuerda que la previsión legal deja sin resolver el problema del acortamiento del mandato del Presidente y el Vicepresidente si dichos cargos se eligiesen, por quedar vacantes, a lo largo del período de tres años entre una y otra renovación parcial del Tribunal. Si ello ocurriese — señala este autor — el propio Tribunal deberá decidir, interpretando su Ley Orgánica, qué solución aplica a estos casos.

${ }_{65}$ En contra de lo que aquí se mantiene se manifiesta J. L. REQUEJO PAGÉS, REDC núm. 83, op. cit., pp. 214 y ss. En su opinión el contenido de la norma es aceptable, pero el instrumento utilizado no es el idóneo. Para este autor tal determinación sólo puede venir establecida por el propio Tribunal Constitucional en uso de la autonomía que le es propia. 
sentados por ellos ${ }^{66}$. Por ese motivo, e independientemente de que la dinámica política de la renovación del Tribunal pueda llevar a «desautorizar una previsión en sí misma sensata ${ }^{67}$, nos parece que tal medida entra plenamente dentro de las materias susceptibles de ser reguladas por esta Ley ${ }^{68}$.

Resulta criticable, desde luego, que la medida legal adoptada se aplicara a la Presidencia en curso. Este hecho pone al descubierto la intencionalidad que la sostiene y que ha producido efectos tan perjudiciales para la imagen pública del $\mathrm{TC}^{69}$. Pero, desde el punto de vista estrictamente jurídico, nos parece acorde con la Constitución, en cuanto viene a poner claridad en una cuestión relativa al funcionamiento y la organización del órgano a la que ni la Constitución, ni la LOTC, ni el Reglamento de Organización y Personal del Tribunal daban respuesta hasta ahora.

${ }^{66}$ En su voto particular, el Magistrado Vicente Conde señala que el Pleno «podía haber elegido a Magistrados de tercios de renovación más lejanos que la inmediata». Pero, siendo cierto esto hasta el momento, parece de una dudosa corrección institucional. Hace alusión igualmente este Magistrado a la posibilidad de que el Presidente, una vez vencido su mandato haya podido perder la confianza de sus pares, estando éstos dispuestos a elegir a otro. Considero que estas razones tienen menor peso que el hecho de que a los Magistrados entrantes se les imponga un Presidente en cuya elección no han participado. Por otro lado, la pérdida de confianza en la persona elegida es una posibilidad con la que hay que contar en toda elección y que puede producirse en cualquier momento y no sólo una vez vencido el mandato.

${ }^{67}$ Cfr. P. CRUZ VILLALÓN (op. cit., pg.11), refiriéndose la prorrogatio de los Magistrados.

${ }^{68}$ A favor de la constitucionalidad de esta regulación se pronuncia también I. TORRES MURO, op. cit., pp. 20 y ss.

${ }^{69}$ La modificación enjuiciada fue introducida por el propio Gobierno en la discusión parlamentaria. Periodísticamente se la ha conocido como «Enmienda Casas», en razón del interés que pudiera tener aquél en la permanencia en el cargo de la Presidenta, María Emilia Casas (y con ella, su voto de calidad en caso de empate) durante el enjuiciamiento del Estatuto catalán, una vez recusado el Magistrado Pérez Tremps.

Sobre esta cuestión v., por ejemplo:

http://www.elmundo.es/papel/2007/07/06/espana/2149047.html.

Por ello, puede comprenderse el malestar que se desprende de lo dispuesto en el voto particular del Magistrado Vicente Conde, en cuanto a que la norma sea aplicable a la presidencia en curso. Señala este Magistrado que, de esta manera, se le impone legalmente al Pleno actual «una dimensión temporal del mandato, que no pudo valorar cuando procedió a la elección».

V., también, J. L. REQUEJO PAGÉS, REDC, núm. 83, op. cit., pg. 216, que se refiere en general al «tormentoso episodio de la reforma de la Ley Orgánica y sus avatares procesales en el propio Tribunal». Señala este autor que éstos han dejado al TC «posiblemente marcado de manera definitiva con el estigma de la politización». En términos no menos pesimistas se manifiesta P. CRUZ VILLALÓN, op. cit., pg. 7. 
Title

THE CONSTITUTIONAL COURT IN FRONT OF THE RECENT REFORM OF THE ARTICLES 16 OF ITS ORGANIC LAW AND 184 OF THE «REGLAMENTO» OF THE SENATE.

\title{
Summary
}

I. INTRODUCTION. II. THE PARTICIPATION OF THE LEGISLATIVE ASSEMBLIES OF THE AUTONOMOUS REGIONS IN THE ELECTION OF THE MAGISTRATES DESIGNATED BY THE SENATE. III. THE STC 49/2008 IN FRONT OF THE NEW THIRD PARAGRAPH OF THE ARTICLE 16 LOTC: EXTENSION OF THE PRESIDENT'S TERM OF OFFICE.

\section{Resumen}

En este trabajo se abordan dos recientes reformas relacionadas con la renovación de los magistrados del Tribunal Constitucional, haciendo especial hincapié en dos aspectos: el de la participación de las Comunidades Autónomas en la elección de los magistrados que corresponden al Senado, y el de la prórroga del mandato del Presidente del Tribunal Constitucional.

\begin{abstract}
This work analyzes two recent reforms related to the renewal of the magistrates of the Constitutional Court, doing special emphasis in two aspects: that of the participation of the Autonomous regions in the election of the magistrates that correspond to the Senate, and that of the extension of the term of office of the President of the Constitutional Court.
\end{abstract}

\section{Palabras clave}

Tribunal Constitucional, Comunidades Autónomas, Presidente del Tribunal Constitucional.

\section{Key Words}

Constitutional Court, Autonomous Regions, President of the Constitutional Court. 